\title{
Regulatory T-cell: Regulator of Host Defense in Infection
}

\author{
Mousa Mohammadnia-Afrouzi ${ }^{1}$, Mehdi Shahbazi ${ }^{1}$, Sedigheh Baleghi Damavandi² ${ }^{2}$ Ghasem Faghanzadeh Ganji ${ }^{3}$, \\ \& Soheil Ebrahimpour ${ }^{2}$ \\ ${ }^{1}$ Department of Immunology, School of Medicine, Babol University of Medical Sciences, Babol, Iran \\ ${ }^{2}$ Infectious Diseases and Tropical Medicine Research Center, Babol University of Medical Sciences, Babol, Iran \\ ${ }^{3}$ Cardiac surgery Department, Rouhani Hospital, Babol University of Medical Sciences, Babol, Iran \\ Correspondence: Soheil Ebrahimpour, Infectious Diseases and Tropical Medicine Research Center, Babol \\ University of Medical Sciences, Babol, Iran. Email: drsoheil1503@yahoo.com. Tel: 989-111-149-309.
}

Received: December 30, 2016

Accepted: January 25, 2017

Online Published: February 3, 2017

doi:10.5539/jmbr.v7n1p9

URL: http://dx.doi.org/10.5539/jmbr.v7n1p9

\begin{abstract}
Based on diverse activities and production of several cytokines, $\mathrm{T}$ lymphocytes and $\mathrm{T}$ helper cells are divided into Th1, Th2, Th17 and regulatory T-cell (T regs) subsets based on diverse activities and production of several cytokines. Infectious agents can escape from host by modulation of immune responses as effector T-cells and Tregs. Thus, regulatory T-cells play a critical role in suppression of immune responses to infectious agents such as viruses, bacteria, parasites and fungi and as well as preserving immune homeostasis. However, regulatory Tcell responses can advantageous for the body by minimizing the tissue-damaging effects. The following subsets of regulatory T-cells have been recognized: natural regulatory Tcells, Th3, Tr1, CD8+ Treg, natural killer like Treg (NKTreg) cells. Among various markers of Treg cells, Forkhead family transcription factor (FOXP3) as an intracellular protein is used for discrimination between activated T reg cells and activated T-cells. FOXP3 has a central role in production, thymocyte differentiation and function of regulatory Tcells. Several mechanisms have been indicated in regulation of $\mathrm{T}$ reg cells. As, the suppression of T-cells via regulatory T-cells is either mediated by Cell-cell contact and Immunosuppressive cytokines (TGF- $\beta$, IL-10) mediated.
\end{abstract}

Keywords: Infection, Immune system, Lymphocytes, Regulatory T-cell

\section{Introduction}

The existence of regulatory T-cell was first suggested over two decades ago, but since then a lot of questions about their structure and function remains unanswered. These cells have the ability to regulate innate and adaptive immune responses, especially cellular immunity (Hasanjani et al., 2016; Ranjbar et al., 2012; Yazdani et al., 2015). Although, it has been proven that Th1 cells are more susceptible to the suppressive activity of Treg cells than Th2 cells (Cools, Ponsaerts, Van Tendeloo, \& Berneman, 2007; Thunberg et al., 2010). These suppressive cells were first recognized by their expression of a phenotype marker called CD25 (IL-2R $\alpha$ chain) .Howbeit, CD25 is an activation marker, it is also present on the surface of the T helper cells, too. Several the subsets of Tregs include natural regulatory T-cells, Th3 cells, Tr1 regulatory cells, CD8+ Treg and natural killer like Treg (NKTreg) cells.

\subsection{Natural Regulatory Tcells (nTregs)}

As a subpopulation of immunoregulatory T-cells , Natural Regulatory Tcells constitutes nearly $5 \%-10 \%$ of CD4+ cells circulating in the bloodstream of humans(Sakaguchi, 2005). In spite of , CD25 is an activation marker of Tcells, less than $5 \%$ of cells with high expression levels of this marker have been proposed as a regulatory agent(Costantino, Baecher-Allan, \& Hafler, 2008). Other markers of nTregs include OX40,CD62 ligand, CTLA4 and Forkhead family transcription factor (FOXP3), among them which only a high level of intracellular FOXP3 is a specific molecular marker for distinction between activated regulatory T-cells and other cells like activated CD4+ T-cells(Hori, Nomura, \& Sakaguchi, 2003). It was proven that the transcription factor FOXP3 has a crucial role in generation, thymocyte differentiation and function of nTregs in mice(Ramsdell \& Ziegler, 2003). There is also correlations exist between lack of FOXP3 protein expression and scurfy in mice or as well as immune dysregulation, polyendocrinopathy, enteropathy and X-linked syndrome (IPEX) in humans(MohammadniaAfrouzi et al., 2015). In other words, the transcription factor FOXP3 is mutated in such like diseases(Gambineri, Torgerson, \& Ochs, 2003; van der Vliet \& Nieuwenhuis, 2007).Contrary to, some recent studies reject the role of this marker in many case of autoimmune diseases(Costantino et al., 2008).Cytokines are type of soluble 
glycoproteins produced by a wide variety of cells, mainly leukocytes within the effector periods of immunity and which regulate immune and inflammatory responses. TGF-beta is a necessary cytokine that is capable of inducing the expression of Foxp3. Bone Morphogenetic Proteins (BMPs) are a specific group of proteins within the members of TGF-beta superfamily, which Smight replace with TGF- $\beta$ during the development of Tregs. As well as, BMPs can also regulate the differentiation, proliferation and apoptosis of various cell types(Ling Lu et al., 2010). Studies on the effect of other cytokines showed that, TNF- $\alpha$ decreases the repressive function of peripheral blood Treg cells in inflammatory bowel diseases (IBD), In so doing, anti-TNF treatment causes to decline in regulatory cells apoptosis or recovery of Tregs percentage(Boschetti et al., 2011; Guidi et al., 2013). IL-15 as a secreted cytokine by mononuclear phagocytes increments expression of regulatory T-cell FOXP3 in the absence of antigenic stimulation. Also it has been shown that FOXP3 expression in the presence of IL-2 and IL-15 compared to IL-7 is significantly increased (Imamichi, Sereti, \& Lane, 2008). IL-27R $\alpha$ is expressed at high levels in the Tregs. IL-27 is capable of binding to IL-27R $\alpha$ as well as promoting nTreg cell expansion in response to IFN$\gamma$ and it is specifically controls of Th1 and as well as expression of CXCR3 on the surface of regulatory cells in intracellular pathogen infections(Hall et al., 2012). IL-2, IL-4 and IL-7 are common gamma chain cytokines. IL-4 and IL-7 are not necessary for the function of nTreg but are important as survival factors(Long \& Buckner, 2008). Compared with them, IL-2 is required for both the activity and homeostasis of nTreg (Zorn et al., 2006). Although, a number of researches do not confirm this issue (Davidson, DiPaolo, Andersson, \& Shevach, 2007).

\subsection{Th3 Regulatory Cells}

This subset of Treg was first isolated from Mesenteric lymph node (MLN) of mice tolerated by low dose antigen feeding(X. Wang et al., 2013). Th3 regulatory cells are dependents upon TGF- $\beta$ and expresses latency-associated peptide (LAP) on own their surface. In the other words, LAP-expressing Tregs are capable of more further suppressive activity in a TGF $\beta$-dependent manner. LAP as a marker be highly expressed on activated Tregs and platelets.(Howard L Weiner, da Cunha, Quintana, \& Wu, 2011) Antigen presenting cells(APCs) induces Th3, however this effect is amplificated by IL-4, IL-10 and TGF $\beta$ (Seder et al., 1998). Among them, TGF- $\beta$ can increase the differentiation of Th3, a process that can be intensified by anti IL-12(Howard L. Weiner, 2001). Albeit, TGF$\beta$ can suppress T-cell proliferation and cytotoxicity. TGF- $\beta 1$ secreted by Th3 is shown to play an incisive role in oral tolerance, as it suppresses of Th1/Th2 balance and cytokine production in Th1(Kim et al., 2004). Th3 cells express another molecule called cytotoxic T-lymphocyte antigen 4 (CTLA-4) on their surface. CTLA-4 cells compete with the binding of B7 ligands to CD28, which inhibit the growth and function of T-cells. Also, CTLA4 as an effective marker has been shown to induce the production TGF- $\beta$, and with increasing proportion of antiCTLA-4 signaling antibody, TGF- $\beta$ production is equally reduced(Myint, Leonard, Steinbusch, \& Kim, 2005). This regulator cells cause to extensive release of IgA antibodies from plasma cells too much. Overall, Th3 has a regulatory role in homeostasis and gastrointestinal diseases(Akbari, Stock, DeKruyff, \& Umetsu, 2003; W. Chen, Jin, \& Wahl, 1998).

\section{$1.3 \operatorname{Tr} 1$ Regulatory Cells}

This subset of regulatory cells is described by a unique cytokine production profile: they produce high levels of TGF- $\beta$ and IL-10 but low levels of IFN- $\gamma$, IL-5 and IL-2(Allan et al., 2008). The cytokine secretion pattern of Tr1 to distinguish it from other T-cells is very helpful. Tr1 cells are capable of controlling immunologic tolerance and auto immune diseases. Some studies showed that IL-10 is a key immunoregulator during viruses, bacteria, parasites infection and decreases immunopathology in many infections. The Th2-associated cytokines IL-4 and IL-13 all perform necessary roles in the pathogenesis of schistosomiasis, with IL-4 and IL-13 directing acute fibrosis. It is has been confirmed that, IL-10 in keeping IL-12 controls Th2 response as described in Schistosoma mansoni involvement(Couper, Blount, \& Riley, 2008).The recent studies indicate the effects of IL-10 on the proliferation and differtiation of human peripheral blood T-cells with inhibition of IL-2 and IL-5 secretion or blocking the production of some chemokines in APCs(Moore, de Waal Malefyt, Coffman, \& O'Garra, 2001). In addition, IL10 is effective on T-cells function via suppression of CD28 (O'Garra, Vieira, Vieira, \& Goldfeld, 2004). IL-10 inhibits the production of proinflammatory cytokines and CD80/86 molecules in monocytes. IgE synthesis in humoral system could be suppressed by this Tr1 cytokine(Meiler, Klunker, Zimmermann, Akdis, \& Akdis, 2008). IL- 6 and IL-27, which are both amplified by TGF- $\beta$, boost the production of IL- 10 by Tr 1 and Th17 cells (Couper et al., 2008). Tr1 cells express some functional markers such as: HLA-DR,CD-40L, IL-15R $\alpha, I L-2 R y$ and various chemokine receptors CCR5, CCR3,CCR8 and CXCR3(Battaglia, Gregori, Bacchetta, \& Roncarolo, 2006). Presence of Tr1 cells in joint fluid and blood specimens from rheumatoid arthritis (RA)patients, confirm this cells effectiveness in immune response(Berthelot \& Maugars, 2004).Role of Tr1 in controlling of type 1 diabetes (T1D) in both of human and mouse model was demonstrated, even the deficiency of Tr1 cells in T1D patients has been investigated (Bettini \& Vignali, 2009). 
Tr1 suppresses the effector cells of allergic inflammation, such as mast cells, eosinophils and basophils. Therefore, some experts emphasize for getting help of $\mathrm{Tr} 1$ in developing new strategies for treatment of allergic diseases(K. $\mathrm{Wu}, \mathrm{Bi}$, Sun, \& Wang, 2007).

\section{4. $C D 8^{+}$Regulatory Cells}

In recent years, another type of suppressor cells has been introduced. These cells are known as $\mathrm{CD} 8^{+}$regulatory cells(H. Jiang \& Chess, 2000). They are not part of $\mathrm{CD}^{+}$regulatory cells and have not cytotoxicity but inhibit the immune response especially TCD $4^{+}$cells in an Ag-specific manner within MHC class I (Vlad, Cortesini, \& SuciuFoca, 2005). CD8 ${ }^{+}$regulatory cells express FOXP3 (not mouse), high levels of CTLA-4 and low level of CD127, which is helpful for differentiation with $\mathrm{CD}^{+} \operatorname{Treg}$ (Fontenot et al., 2005; Scotto et al., 2004). Many studies were showed that $\mathrm{CD} 8^{+}$regulatory cells expressed glucocorticoid-induced tumor necrosis factor receptor (GITR) and tumor necrosis factor receptor 2 (TNFR2), which were identified in human thymus(Cosmi et al., 2003). Usefulness of these cells in treatment was first demonstrated in animal models of multiple sclerosis (MS) and experimental autoimmune encephalomyelitis (EAE)(Linrong Lu \& Cantor, 2008). Some researches demonstrate that CD8 regulatory cells are presented in the lamina proparia of healthy cases, but not in IBD patients, suggesting that these cells might play a crucial role in immune tolerance in this involvement or in several cancers(Brimnes et al., 2005; Dinesh, Skaggs, Cava, Hahn, \& Singh, 2010).

\subsection{NKT Regulatory Cells}

Several researchers have proposed other names for these cells, including natural T-cells, V $\alpha 14 \mathrm{i}$ T-cells and iNKTcells. Although NKT-cells has been accepted and is now used to refer to these suppressive cells, because they simultaneously express some markers of NKcells and T-cells. These markers contain CD161(human), NK1.1( mouse),CD16 and IL-2Rß as NKcells marker and TCRs belonging Tcells (Godfrey, MacDonald, Kronenberg, Smyth, \& Van Kaer, 2004). NKT-cells are localized in various tissues like liver, bone marrow, lung and spleen. Thus, these cells observe within account for $50 \%$ of T-cells in the liver, $30 \%$ in the bone marrow, $7 \%$ in lung and $3 \%$ in spleen(Tarazona et al., 2003). Other types of these cells according to expressing of CD markers are included $\mathrm{CD} 4^{+} \mathrm{NKT}, \mathrm{CD} 8^{+} \mathrm{NKT}$ and $\mathrm{CD} 4^{-} \mathrm{CD} 8^{-} \mathrm{NKT}$ cells(DN). $\mathrm{CD} 4^{+} \mathrm{NKT}$ cells are able to produce cytokines of Th1 and Th2 concurrent, but CD4- CD8-NKTcells are only capable of generating cytokines of Th1 cells (Cava, Kaer, \& Fu Dong, 2006). NKT regulatory cells can produce high levels of cytokines like IL-17, IL-22، IFN- $\gamma$, IL-4 ,IL-13 and TGF- $\beta$ thus, effect on Dendritic cells 'NKcells 'helper Tcells and Bcells or regulate innate and acquired immunity(Parekh, $\mathrm{Wu}$, Olivares-Villagómez, Wilson, \& Van Kaer, 2013).Proliferation of memory Th1 cells and memory Th2 cells is upregulated by NKT regulatory cells, moreover IL-4 produced by these cells can effect on proliferation and differentiation of Th2. Surprisingly, NKT-cells promote nTregs proliferation by producing of soluble IL-2, but in some cases nTregs regulate NKTcells(S. Jiang, Game, Davies, Lombardi, \& Lechler, 2005). Contrary to NKcells, cytotoxicity of NKTcells has not confirmed, though these cells induce high proportions of CD95L and perforin(Smyth et al., 2002). NKT regulatory cells play major role in regulation of immune responses in allergy, infection and cancer. Many studies have showed that the proportion of NKT regulatory cells increased in the lung after Mycobacterial and Streptococcus pneumoniae infections (Iwamura et al., 2012).

\section{Mechanism of Suppression}

Although, the crucial role of Tregs in regulation of physiologic and pathologic responses including anti tumor and anti bacterial effects has confirmed but, no clearly description has been presented for mechanism of Tregs suppression. Suppression of T-cells is either mediated by cell-cell contact and immunosuppressive cytokines.

\subsection{Cell-Cell Contact}

Natural (human) Tregs and $\mathrm{CD} 4{ }^{+} \mathrm{CD} 25^{+}$(mouse) Tregs express CTLA-4 or CD152. It has been postulated that CD152 is necessary for the function of these cells. CTLA-4 competes with CD28 for binding to B7. The affinity of CTLA4 for B7 was estimated to be about 10 folds higher than the affinity of CD28 for this ligand. T-cell proliferation is inhibited by binding of CTLA-4 to B7, in other words CTLA-4 plays an important role in T-cell peripheral tolerance(Salomon et al., 2000). Tregs stimulate dendritic cells (DCs) to express the enzyme indoleamine 2,3dioxygenase (IDO) or IDO production is resulted from interactions between CTLA-4 and B7 ligands. Although, these cells may block the expression of B7-1 and B7-2 on some APCs(Sakaguchi, Wing, Onishi, Prieto-Martin, \& Yamaguchi, 2009). IDO Serves tryptophan to kynurenine, leading to destruction of T-cells and also to direcT-cell cycle suppression. Many researches were showed that IDO causes to tryptophan degradation and suppress the immunity response to tumors(Soliman, Mediavilla-Varela, \& Antonia, 2010). Autoimmune disorders widely occur in CTLA-4 deficient mice widely and the ability of repression in Treg is reduced(Vogel et al., 2015). Moreover, CTLA-4/CD80.86 interactions to the control of colitis were clearly described(Sojka, Huang, \& Fowell, 2008). 


\subsection{Immunosuppressive Cytokine Mediated Suppression}

TGF- $\beta$ and IL-10 have great role in the suppression of immune system. TGF $\beta$ decreases the expression of MHC class II in macrophages and DCs. In astrocyte ( a sub-type of glial cells in the central nervous system or CNS), class II MHC transactivator (CIITA), as a suppressor that regulates MHCII expression, is targeted by TGF- $\beta$ for repression of MHCII expression(Dong, Tang, Letterio, \& Benveniste, 2001). Totally, TGF- $\beta$ suppresses immunity system via in two manners: promoting the function of Treg cells especially in autoimmune diseases and suppression of inflammatory cells. It should be noted that , the role of TGF- $\beta$ in Tregs suppression is still an issue of argument(Oberle, Eberhardt, Falk, Krammer, \& Suri-Payer, 2007). In preliminary mechanism of suppression, IL-10 inhibits the expression of cell surface MHC II by macrophages. In this regard, IL-10 diminishes mRNA as to MHC II and expression of this MHC in peritoneal macrophage (Chadban et al., 1998). Contrary, IFN- $\gamma$ stimulates the expression of MCHII molecules on mesangial cells and IL-10 and TGF- $\beta$ regulate this function(Gattoni, Parlato, Vangieri, Bresciani, \& Derna, 2006). Other cytokines like IL-35 are produced by Tregs (Bardel, Larousserie, Charlot-Rabiega, Coulomb-L'Herminé, \& Devergne, 2008; Collison et al., 2007). In cancer cells, IL-35 increases the expression of gp130 and decreases sensitivity to cytotoxic T-cell (CTL) demolition. More over IL-35 promotes tumor angiogenesis(Z. Wang et al.).

\section{Regulatory T-cell and Infection}

\subsection{Regulatory T-cells in Viral Infections}

It is confirmed that infections are associated with various regulatory cells and their cytokines. For example, IL-10 plays a key role in several disorders, including ; hepatitis C, Tuberculosis and Leishmaniasis, as a suppressor of immune systems(Wohlfert \& Belkaid, 2008). TCD $8^{+}$cell response during acute viral infection is necessary for elimination of virus. But however, Tregs cause to limit in this function and some experiments were showed that clearing the viruses is accelerated without regulatory cells. Virus-specific T-cells can cause to damage to the host tissues, but Treg cells prevent tissues damage and are beneficial. Increase in regulatory T-cells has been shown to suppressive activity in the acute form of HCV patients(Sugimoto et al., 2003). These regulatory cells may also protect the patients from pathologic disorders and viral-induced inflammation in chronic HCV infection(Claassen, de Knegt, Tilanus, Janssen, \& Boonstra, 2010). The level of circulating CD4 ${ }^{+} \mathrm{CD} 25^{+}$Treg cells is enhanced in chronic hepatitis B patients since, these lymphocytes are able to inhibit production of cytokines production such as IFN- $\gamma$ and proliferation of other T-cells. Many researches showed that the frequency of CD4 $4^{+} \mathrm{CD} 25^{+}$Treg cells is positively correlated with serum viral load of hepatitis B(Peng et al., 2008). In herpes simplex virus (HSV) infection, the regulatory function of $\mathrm{CD} 4{ }^{+} \mathrm{CD} 25^{+}$Treg cells is clearly observed. In the other words, regulatory Tcells impairs immunity to herpes simplex virus which is depended upon $\mathrm{CD} 8^{+} \mathrm{T}$-cell response(Rouse, Sarangi, \& Suvas, 2006). This was supported by the fact that, depletion of Tregs from cases with HSV infection significantly enhanced the protective immunity(Fernandez et al., 2008). In HIV infection the level of regulatory T-cells in lymph nodes and blood may be significantly high. Treg cells mainly suppress cytokines secretion of $\mathrm{CD}^{+} \mathrm{T}$-cells and cytolytic activity of $\mathrm{CD} 8^{+}$effector T-cells in acute phase of infection more than chronic phase(Thorborn et al., 2010). According to some studies, presence of viraemia in chronic HIV infection is correlated with the reduction of circulating regulatory T-cells which is useful to enhancement of $\mathrm{CD} 4^{+} \mathrm{T}$-cells function(Baker et al., 2007). Overall, researches indicate that chronic viral infection cause to induce regulatory T-cells which are implicated in the regulation and impairment of antiviral immune responses.

\subsection{Regulatory T-cells in Bacterial Infections}

In bacterial infections like active form of tuberculosis (TB), Treg cells meaningfully expand in the lung, blood and lymph nodes relative to healthy or latent cases (Y. E. Wu et al., 2010). $\mathrm{CD}^{+} \mathrm{CD} 25^{+} \mathrm{FoxP}^{+} \mathrm{T}$-cells are able to suppressing IL-10 and IFN- $\gamma$ production in TB patients(Xinchun Chen et al., 2007). Regulatory T-cells prevent from disruption of tubercle bacilli by suppressing efficient $\mathrm{CD}^{+}{ }^{+} \mathrm{T}$-cell response in $\mathrm{TB}$. In these infections like viral disorders, Tregs have some beneficially aspects for host, as could they permit a long-term persistence of M. tuberculosis and thus a relative maintained immunity against re-infection(Majlessi, Lo-Man, \& Leclerc, 2008). In Bordetella pertussis infection, the virulence factor of these bactria is toxin (PTx). This toxin causes to enhanced function of regulatory T-cells and promoted in TGF- $\beta$ in the serum of cases and thus Bordetella pertussis inhibits Th1 response(Weber et al., 2010). Also other studies showed that PTx cause to down-regulation of the percentage and function of Treg cells and this element is used to induce murine experimental autoimmune encephalomyelitis (EAE)(Xin Chen et al., 2006). During infection with Brucella abortus, similar to other infectious models, there is increase in both effector $\mathrm{CD}^{+}$T-cells and regulatory T-cells in the spleen of BALB/c mice(Pasquali et al., 2010). Due to this fact, Treg cells inhibit Th1 activity and used to process of infection (Hasanjani-Roushan, Kazemi, FallahRostami, \& Ebrahimpour; Kazemi, Damavandi, \& Ebrahimpour, 2015; Roushan, Kazemi, Rostam, \& Ebrahimpour, 
2014). Furthermore, this is showed that the percentage of regulatory T-cells was shown to be elevated in several forms of human brucellosis, and also, this increment being rather in the chronic patients(Bahador et al., 2014). CD4 ${ }^{+} \mathrm{CD} 25^{+} \mathrm{T}$ regulatory cells, which produce IL-10 mediated alteration in macrophages function, therefore impede $\mathrm{CD}^{+} \mathrm{T}$-cell response. In infection with Salmonella Typhimurium, when the bacterial burden is increasing, Treg cells suppress the activity and proliferation of some immune cells But, when bacterial load is decreased, the suppression ability of Treg cells is declined(Johanns, Ertelt, Rowe, \& Way, 2010).

\subsection{Regulatory T-cells in Parasitic Infections}

In parasitic infection, immune response depends on activity of Th2 and cytokines as IL-4, IL-5 and IL-13. CD4 ${ }^{+}$ $\mathrm{CD} 25^{+} \mathrm{Foxp}^{+}$Treg numbers can expand following parasitic infections. The balance between Treg cells and Th1, Th2 responses is critical in the defense against parasites. Chagas disease is an infection caused by a protozoan parasite called Trypanosoma cruzi and the infection is associated with immunoregulation of cellular and humoral immunity via Treg cells which incapacitate the infected macrophages(Flores-García, Rosales-Encina, RosalesGarcía, Satoskar, \& Talamás-Rohana, 2012). Otherwise, $\mathrm{CD} 4{ }^{+} \mathrm{CD} 25^{\text {High }}$ Treg cells could be limiting the damage to host and leading to durability of the clinical forms in this infection(Sathler-Avelar, Vitelli-Avelar, TeixeiraCarvalho, \& Martins-Filho, 2009). Many studies administrated that $\mathrm{CD} 4{ }^{+} \mathrm{CD} 25^{+}$Foxp3 Treg cells are enhanced in peripheral blood of schistosomiasis patients and modulate the activity of effector Th1 and Th2 responses with suppression of the responsiveness of IFN $\gamma$, IL-4 and IL-5. Treg cells play significant roles in minimizing pathological effects during schistosomiasis (Nausch, Midzi, Mduluza, Maizels, \& Mutapi, 2011).Elevated $\mathrm{CD} 4^{+} \mathrm{CD} 25^{+} \mathrm{Foxp}^{+}$Tregs producing both IL-10 and TGF- $\beta$ contribute to regulation of immune responses during the primary stage of cutaneous leishmaniasis. Moreover, active lesions are presented in patients with polarized Th2 responses and also are correlated with increased IL-10 production. Thus, regulatory T-cells prohibit complete elimination of parasites from the skin of host, during cure of infection (Nylén \& Sacks, 2007).

\subsection{Regulatory T-cells in Fungal Infections}

Aspergillosis is caused by the spores of Aspergillus, and can occur depending on the functions of Th 1, Th2, Th17, and regulatory T-cells. CD4 ${ }^{+}$T-cells can protect the host against invasive aspergillosis (Bozza et al., 2009). Treg cells prevent innate immune cells and effector Tcells by suppressing the production of inflammatory cytokines. Thus, activation and expansion of Treg cells able to regulate neutrophils within the action of IL-10 on indoleamine 2,3-dioxygenase(IDO) that leads to control of inflammation in this fungal infection(Montagnoli et al., 2006). Some studies showed a higher percentage of $\mathrm{CD} 4{ }^{+} \mathrm{CD} 25^{+} \mathrm{Foxp}^{+} \mathrm{T}$-cells and increased GITR expression levels of these cells in cases with active paracoccidioidomycosis (an infection caused by the dimorphic fungus Paracoccidioides brasiliensis) and also indicated that after adequate antifungal therapy, the levels of regulatory T-cells was declined in the circulation (Ferreira, de Oliveira, da Silva, Blotta, \& Mamoni, 2010). Furthermore, an important receptor called CCR5 caused to migration of regulatory T-cells to the lesions of paracoccidioidomycosis, leading to suppression of immune response and lasting attendance of Paracoccidioides brasiliensis in the granulomas (Moreira et al., 2008). So, a useful mechanism for avoiding the intensity of infection is regulation of this migration to the lesions. In Candida albicans infection, the immune response contains production of cytokines as IL-1, IL17A and IFN- $\gamma$ (Zelante et al., 2007). Th1 cells are associated with protection from this infection. However, the presence of regulatory T-cells inhibits clearance of C. albicans with macrophages. Contrary to , other studies administrated that in C. albicans involvements, elevated percentage of Treg cells correlated to protection from infection, as in some autoimmune diseases with faulty regulatory Tcells, mucocutaneous candidiasis were observed (Whibley et al., 2014).

Table 1. Alteration of Tregs level in different diseases

\begin{tabular}{lcl}
\hline Disease & Treg & \multicolumn{1}{c}{ Reference } \\
\hline Viral infection & Increased & (Maizels \& Smith, 2011) \\
Bacterial infection & Increased & (Belkaid \& Rouse, 2005; Y. E. Wu et al., 2010) \\
Parasitic infection & Increased & (Belkaid, 2007) \\
Fungi infection & Increased & (Ferreira et al., 2010; Romani, 2004) \\
Multiple sclerosis & Normal or decreased & (Haas et al., 2007; Huan et al., 2005) \\
Idiopathic thrombocytopenic purpura (ITP) & Decreased & (Lv, Liu, \& Wu, 2007) \\
Type 1 diabetes & Decreased & (Lindley et al., 2005) \\
Ulcerative colitis & Normal or decreased & (Takahashi et al., 2006) \\
Cancer & Increased & (Mougiakakos, Choudhury, Lladser, Kiessling, \& \\
& & Johansson, 2010) \\
\hline
\end{tabular}




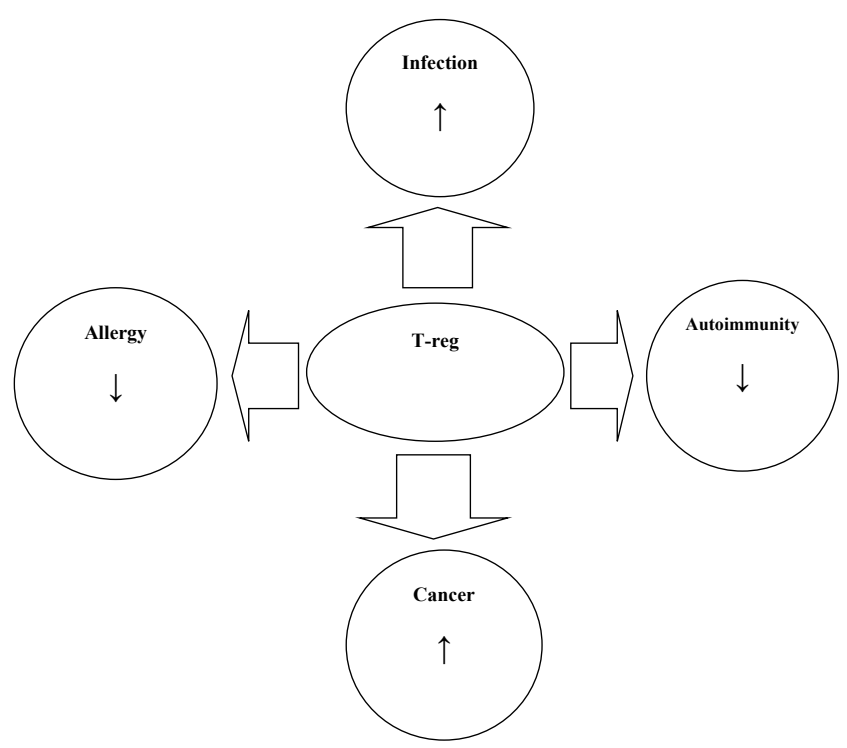

Figure 1. Level of regulatory T-cells in different disorders

In conclusion, in spite of many studies on control and suppression of immune system including cells and tissues involved, many questions regarding to aspects of these issues remain unanswered. According to currently discussed text, Treg cells play a dual role as immune regulatory cells are dual, thus these cells suppress infectious immune response and also moderateing the immunopathologic effects of some disease causing agents. Of course, it seems that inadequacy of the advantage of this simple protection. Such abilities of the Treg cells in association with the infectious immune responses make them remarkable models to achieve new strategies in the treatment of infectious diseases.

\section{Acknowledgments}

The authors would like to thank the staffs of departments of immunology and infectious diseases for their sincere cooperation in this project.

\section{References}

Akbari, O., Stock, P., DeKruyff, R. H., \& Umetsu, D. T. (2003). Role of regulatory T cells in allergy and asthma. Current Opinion in Immunology, 15(6), 627-633. doi: http://dx.doi.org/10.1016/j.coi.2003.09.012

Allan, S. E., Broady, R., Gregori, S., Himmel, M. E., Locke, N., Roncarolo, M. G., ... Levings, M. K. (2008). CD4+ T-regulatory cells: toward therapy for human diseases. Immunological reviews, 223(1), 391-421.

Bahador, A., Hadjati, J., Hassannejad, N., Ghazanfari, H., Maracy, M., Jafari, S., ... Nejadeh, A. (2014). Frequencies of CD4+ T Regulatory Cells and their CD25high and FoxP3high Subsets Augment in Peripheral Blood of Patients with Acute and Chronic Brucellosis. Osong Public Health and Research Perspectives, 5(3), 161-168. doi: http://dx.doi.org/10.1016/j.phrp.2014.04.008

Baker, C., Clark, R., Ventura, F., Jones, G., Guzman, D., Bangsberg, R., \& Cao, H. (2007). Peripheral CD4 loss of regulatory $\mathrm{T}$ cells is associated with persistent viraemia in chronic HIV infection. Clinical \& Experimental Immunology, 147(3), 533-539.

Bardel, E., Larousserie, F., Charlot-Rabiega, P., Coulomb-L'Herminé, A., \& Devergne, O. (2008). Human CD4+ CD25+ Foxp3+ regulatory T cells do not constitutively express IL-35. The Journal of immunology, 181(10), 6898-6905.

Battaglia, M., Gregori, S., Bacchetta, R., \& Roncarolo, M.-G. (2006). Tr1 cells: from discovery to their clinical application. Paper presented at the Seminars in immunology.

Belkaid, Y. (2007). Regulatory T cells and infection: a dangerous necessity. Nature Reviews Immunology, 7(11), 875-888.

Belkaid, Y., \& Rouse, B. T. (2005). Natural regulatory T cells in infectious disease. Nature immunology, 6(4), 353-360. 
Berthelot, J.-M., \& Maugars, Y. (2004). Role for suppressor T cells in the pathogenesis of autoimmune diseases (including rheumatoid arthritis). Facts and hypotheses. Joint Bone Spine, 71(5), 374-380.

Bettini, M., \& Vignali, D. A. (2009). Regulatory T cells and inhibitory cytokines in autoimmunity. Current opinion in immunology, 21(6), 612-618.

Boschetti, G., Nancey, S., Sardi, F., Roblin, X., Flourie, B., \& Kaiserlian, D. (2011). Therapy with anti-TNFalpha antibody enhances number and function of Foxp3(+) regulatory $\mathrm{T}$ cells in inflammatory bowel diseases. Inflamm Bowel Dis, 17(1), 160-170. doi: 10.1002/ibd.21308

Bozza, S., Clavaud, C., Giovannini, G., Fontaine, T., Beauvais, A., Sarfati, J., ... Zagarella, S. (2009). Immune sensing of Aspergillus fumigatus proteins, glycolipids, and polysaccharides and the impact on Th immunity and vaccination. The Journal of immunology, 183(4), 2407-2414.

Brimnes, J., Allez, M., Dotan, I., Shao, L., Nakazawa, A., \& Mayer, L. (2005). Defects in CD8+ regulatory T cells in the lamina propria of patients with inflammatory bowel disease. The Journal of immunology, 174(9), 58145822.

Cava, A. L., Kaer, L. V., \& Fu Dong, S. (2006). CD4+CD25+ Tregs and NKT cells: regulators regulating regulators. Trends in Immunology, 27(7), 322-327. doi: http://dx.doi.org/10.1016/j.it.2006.05.003

Chadban, S. J., Tesch, G. H., Foti, R., Lan, H. Y., Atkins, R. C., \& Nikolic-Paterson, D. J. (1998). Interleukin-10 differentially modulates MHC class II expression by mesangial cells and macrophages in vitro and in vivo. Immunology, 94(1), 72-78.

Chen, W., Jin, W., \& Wahl, S. M. (1998). Engagement of cytotoxic T lymphocyte-associated antigen 4 (CTLA4) induces transforming growth factor $\beta$ (TGF- $\beta$ ) production by murine CD4+ T cells. The Journal of experimental medicine, 188(10), 1849-1857.

Chen, X., Winkler-Pickett, R. T., Carbonetti, N. H., Ortaldo, J. R., Oppenheim, J. J., \& Howard, O. (2006). Pertussis toxin as an adjuvant suppresses the number and function of $\mathrm{CD} 4+\mathrm{CD} 25+\mathrm{T}$ regulatory cells. European journal of immunology, 36(3), 671-680.

Chen, X., Zhou, B., Li, M., Deng, Q., Wu, X., Le, X., ... Katsanis, E. (2007). CD4+CD25+FoxP3+ regulatory T cells suppress Mycobacterium tuberculosis immunity in patients with active disease. Clinical Immunology, 123(1), 50-59. doi: http://dx.doi.org/10.1016/j.clim.2006.11.009

Claassen, M. A., de Knegt, R. J., Tilanus, H. W., Janssen, H. L., \& Boonstra, A. (2010). Abundant numbers of regulatory $\mathrm{T}$ cells localize to the liver of chronic hepatitis $\mathrm{C}$ infected patients and limit the extent of fibrosis. Journal of hepatology, 52(3), 315-321.

Collison, L. W., Workman, C. J., Kuo, T. T., Boyd, K., Wang, Y., Vignali, K. M., ... Vignali, D. A. (2007). The inhibitory cytokine IL-35 contributes to regulatory T-cell function. Nature, 450(7169), 566-569.

Cools, N., Ponsaerts, P., Van Tendeloo, V. F., \& Berneman, Z. N. (2007). Balancing between immunity and tolerance: an interplay between dendritic cells, regulatory $\mathrm{T}$ cells, and effector T cells. Journal of leukocyte biology, 82(6), 1365-1374.

Cosmi, L., Liotta, F., Lazzeri, E., Francalanci, M., Angeli, R., Mazzinghi, B., ... Romagnani, P. (2003). Human CD8+ CD25+ thymocytes share phenotypic and functional features with CD4+ CD25+ regulatory thymocytes. Blood, 102(12), 4107-4114.

Costantino, C. M., Baecher-Allan, C. M., \& Hafler, D. A. (2008). Human regulatory T cells and autoimmunity. European journal of immunology, 38(4), 921-924.

Couper, K. N., Blount, D. G., \& Riley, E. M. (2008). IL-10: the master regulator of immunity to infection. The Journal of immunology, 180(9), 5771-5777.

Davidson, T. S., DiPaolo, R. J., Andersson, J., \& Shevach, E. M. (2007). Cutting edge: IL-2 is essential for TGF$\beta$-mediated induction of Foxp3+ T regulatory cells. The Journal of immunology, 178(7), 4022-4026.

Dinesh, R. K., Skaggs, B. J., Cava, A. L., Hahn, B. H., \& Singh, R. P. (2010). CD8(+) Tregs in Lupus, Autoimmunity, and Beyond. Autoimmunity reviews, 9(8), 560-568. doi: 10.1016/j.autrev.2010.03.006

Dong, Y., Tang, L., Letterio, J. J., \& Benveniste, E. N. (2001). The Smad3 protein is involved in TGF- $\beta$ inhibition of class II transactivator and class II MHC expression. The Journal of immunology, 167(1), 311-319. 
Fernandez, M. A., Puttur, F. K., Wang, Y. M., Howden, W., Alexander, S. I., \& Jones, C. A. (2008). T regulatory cells contribute to the attenuated primary CD8+ and CD4+ T cell responses to herpes simplex virus type 2 in neonatal mice. The Journal of immunology, 180(3), 1556-1564.

Ferreira, M. C., de Oliveira, R. T. D., da Silva, R. M., Blotta, M. H. S. L., \& Mamoni, R. L. (2010). Involvement of regulatory $\mathrm{T}$ cells in the immunosuppression characteristic of patients with paracoccidioidomycosis. Infection and immunity, 78(10), 4392-4401.

Flores-García, Y., Rosales-Encina, J. L., Rosales-García, V. H., Satoskar, A. R., \& Talamás-Rohana, P. (2012). Treg Cells Induced by rSSP4 Derived from T. cruzi Amastigotes Increase Parasitemia in an Experimental Chagas Disease Model. BioMed research international, 2013.

Fontenot, J. D., Rasmussen, J. P., Williams, L. M., Dooley, J. L., Farr, A. G., \& Rudensky, A. Y. (2005). Regulatory $\mathrm{T}$ cell lineage specification by the forkhead transcription factor foxp3. Immunity, 22(3), 329-341.

Gambineri, E., Torgerson, T. R., \& Ochs, H. D. (2003). Immune dysregulation, polyendocrinopathy, enteropathy, and X-linked inheritance (IPEX), a syndrome of systemic autoimmunity caused by mutations of FOXP3, a critical regulator of T-cell homeostasis. Current opinion in rheumatology, 15(4), 430-435.

Gattoni, A., Parlato, A., Vangieri, B., Bresciani, M., \& Derna, R. (2006). Interferon-gamma: biologic functions and HCV therapy (type I/II) (1 of 2 parts). Clin Ter, 157(4), 377-386.

Godfrey, D. I., MacDonald, H. R., Kronenberg, M., Smyth, M. J., \& Van Kaer, L. (2004). NKT cells: what's in a name? Nature Reviews Immunology, 4(3), 231-237.

Guidi, L., Felice, C., Procoli, A., Bonanno, G., Martinelli, E., Marzo, M., ... Rutella, S. (2013). FOXP3(+) T regulatory cell modifications in inflammatory bowel disease patients treated with anti-TNFalpha agents. Biomed Res Int, 2013, 286368. http://dx.doi.org/10.1155/2013/286368

Haas, J., Fritzsching, B., Trübswetter, P., Korporal, M., Milkova, L., Fritz, B., ... Wildemann, B. (2007). Prevalence of newly generated naive regulatory T cells (Treg) is critical for Treg suppressive function and determines Treg dysfunction in multiple sclerosis. The Journal of immunology, 179(2), 1322-1330.

Hall, Aisling O. H., Beiting, Daniel P., Tato, C., John, B., Oldenhove, G., Lombana, Claudia G., ... Hunter, Christopher A. (2012). The Cytokines Interleukin 27 and Interferon- $\gamma$ Promote Distinct Treg Cell Populations Required to Limit Infection-Induced Pathology. Immunity, 37(3), 511-523. http://dx.doi.org/10.1016/j. immuni.2012.06.014

Hasanjani-Roushan, M. R., Kazemi, S., Fallah-Rostami, F., \& Ebrahimpour, S. Brucellosis Vaccines: An Overview. Crescent Journal of Medical and Biological Sciences, 1(4), 118-124.

Hasanjani, R. M., Bayani, M., Soleimani, A. S., Mohammadnia-Afrouzi, M., Nouri, H., \& Ebrahimpour, S. (2016). Evaluation of CD4+ CD25+ FoxP3 + regulatory T cells during treatment of patients with brucellosis. Journal of biological regulators and homeostatic agents, 30(3), 675.

Hori, S., Nomura, T., \& Sakaguchi, S. (2003). Control of regulatory T cell development by the transcription factor Foxp3. Science, 299(5609), 1057-1061.

Huan, J., Culbertson, N., Spencer, L., Bartholomew, R., Burrows, G. G., Chou, Y. K., ... Vandenbark, A. A. (2005). Decreased FOXP3 levels in multiple sclerosis patients. Journal of neuroscience research, 81(1), 45-52.

Imamichi, H., Sereti, I., \& Lane, H. C. (2008). IL-15 acts as a potent inducer of CD4+CD25hi cells expressing FOXP3. European journal of immunology, 38(6), 1621-1630. doi: 10.1002/eji.200737607

Iwamura, C., Shinoda, K., Endo, Y., Watanabe, Y., Tumes, D. J., Motohashi, S., ... Nakayama, T. (2012). Regulation of memory CD4 T-cell pool size and function by natural killer T cells in vivo. Proceedings of the National Academy of Sciences, 109(42), 16992-16997.

Jiang, H., \& Chess, L. (2000). The specific regulation of immune responses by CD $8+$ T cells restricted by the MHC class Ib molecule, Qa-1. Annual review of immunology, 18(1), 185-216.

Jiang, S., Game, D. S., Davies, D., Lombardi, G., \& Lechler, R. I. (2005). Activated CD1d-restricted natural killer T cells secrete IL-2: innate help for CD4+ CD25+ regulatory T cells? European journal of immunology, 35(4), 1193-1200.

Johanns, T. M., Ertelt, J. M., Rowe, J. H., \& Way, S. S. (2010). Regulatory T cell suppressive potency dictates the balance between bacterial proliferation and clearance during persistent Salmonella infection. PLoS Pathog, 6(8), e1001043. 
Kazemi, S., Damavandi, S. B., \& Ebrahimpour, S. (2015). Letter to Editor-macrophages and Brucella Infection. infection, 1(3), 69-75.

Kim, Y.-K., Myint, A.-M., Lee, B.-H., Han, C.-S., Lee, H.-J., Kim, D.-J., \& Leonard, B. E. (2004). Th1, Th2 and Th3 cytokine alteration in schizophrenia. Progress in Neuro-Psychopharmacology and Biological Psychiatry, 28(7), 1129-1134. doi: http://dx.doi.org/10.1016/j.pnpbp.2004.05.047

Lindley, S., Dayan, C. M., Bishop, A., Roep, B. O., Peakman, M., \& Tree, T. I. (2005). Defective suppressor function in CD4+ CD25+ T-cells from patients with type 1 diabetes. Diabetes, 54(1), 92-99.

Long, S. A., \& Buckner, J. H. (2008). Combination of rapamycin and IL-2 increases de novo induction of human CD4+CD25+FOXP3+ T cells. Journal of Autoimmunity, 30(4), 293-302. doi: http://dx.doi.org/10.1016/j.jaut. 2007.12.012

Lu, L., \& Cantor, H. (2008). Generation and regulation of CD8+ regulatory T cells.

Lu, L., Ma, J., Wang, X., Wang, J., Zhang, F., Yu, J., ... Horwitz, D. A. (2010). Synergistic effect of TGF- $\beta$ superfamily members on the induction of Foxp3+ Treg. European journal of immunology, 40(1), 142-152.

Lv, X.-w., Liu, F., \& Wu, C.-1. (2007). Eexpression of Foxp3 and CD4^+ CD 2 $5^{\wedge}+$ Regulation T Cells in Children with Acute Idiopathic Thrombocytopenic Purpura. Journal of Applied Clinical Pediatrics, 22(3), 188.

Maizels, R. M., \& Smith, K. A. (2011). Regulatory T cells in infection. Adv Immunol, 112, 73-136.

Majlessi, L., Lo-Man, R., \& Leclerc, C. (2008). Regulatory B and T cells in infections. Microbes and Infection, 10(9), 1030-1035. doi: http://dx.doi.org/10.1016/j.micinf.2008.07.017

Meiler, F., Klunker, S., Zimmermann, M., Akdis, C. A., \& Akdis, M. (2008). Distinct regulation of IgE, IgG4 and IgA by T regulatory cells and toll-like receptors. Allergy, 63(11), 1455-1463.

Mohammadnia-Afrouzi, M., Zavaran Hosseini, A., Khalili, A., Abediankenari, S., Hosseini, V., \& Maleki, I. (2015). Decrease of CD4+CD25+CD127low FoxP3 + regulatory T cells with impaired suppressive function in untreated ulcerative colitis patients. Autoimmunity, 48(8), 556-561.

Montagnoli, C., Fallarino, F., Gaziano, R., Bozza, S., Bellocchio, S., Zelante, T., ... Romani, L. (2006). Immunity and tolerance to Aspergillus involve functionally distinct regulatory $\mathrm{T}$ cells and tryptophan catabolism. The Journal of immunology, 176(3), 1712-1723.

Moore, K. W., de Waal Malefyt, R., Coffman, R. L., \& O'Garra, A. (2001). Interleukin-10 and the interleukin-10 receptor. Annual review of immunology, 19(1), 683-765.

Moreira, A. P., Cavassani, K. A., Massafera Tristão, F. S., Campanelli, A. P., Martinez, R., Rossi, M. A., \& Silva, J. S. (2008). CCR5-dependent regulatory $\mathrm{T}$ cell migration mediates fungal survival and severe immunosuppression. J Immunol, 180(5), 3049-3056.

Mougiakakos, D., Choudhury, A., Lladser, A., Kiessling, R., \& Johansson, C. C. (2010). Regulatory T cells in cancer. Advances in cancer research, 107, 57-117.

Myint, A.-M., Leonard, B. E., Steinbusch, H. W. M., \& Kim, Y.-K. (2005). Th1, Th2, and Th3 cytokine alterations in major depression. Journal of Affective Disorders, 88(2), 167-173. doi: http://dx.doi.org/10.1016/j.jad.2005. 07.008

Nausch, N., Midzi, N., Mduluza, T., Maizels, R. M., \& Mutapi, F. (2011). Regulatory and Activated T Cells in Human $<$ italic $>$ Schistosoma haematobium $</$ italic $>$ Infections. PLoS One, 6(2), e16860. http://dx.doi.org/ 10.1371/journal.pone. 0016860

Nylén, S., \& Sacks, D. (2007). Interleukin-10 and the pathogenesis of human visceral leishmaniasis. Trends in Immunology, 28(9), 378-384. http://dx.doi.org/10.1016/j.it.2007.07.004

O'Garra, A., Vieira, P. L., Vieira, P., \& Goldfeld, A. E. (2004). IL-10-producing and naturally occurring CD4+ Tregs: limiting collateral damage. Journal of Clinical Investigation, 114(10), 1372.

Oberle, N., Eberhardt, N., Falk, C. S., Krammer, P. H., \& Suri-Payer, E. (2007). Rapid suppression of cytokine transcription in human $\mathrm{CD} 4+\mathrm{CD} 25 \mathrm{~T}$ cells by $\mathrm{CD} 4+\mathrm{Foxp} 3+$ regulatory $\mathrm{T}$ cells: independence of IL-2 consumption, TGF-beta, and various inhibitors of TCR signaling. J Immunol, 179(6), 3578-3587.

Parekh, V. V., Wu, L., Olivares-Villagómez, D., Wilson, K. T., \& Van Kaer, L. (2013). Activated invariant NKT cells control central nervous system autoimmunity in a mechanism that involves myeloid-derived suppressor cells. The Journal of immunology, 190(5), 1948-1960. 
Pasquali, P., Thornton, A. M., Vendetti, S., Pistoia, C., Petrucci, P., Tarantino, M., ... Shevach, E. M. (2010). CD4+ $\mathrm{CD} 25+\mathrm{T}$ regulatory cells limit effector $\mathrm{T}$ cells and favor the progression of brucellosis in BALB/c mice. Microbes and Infection, 12(1), 3-10.

Peng, G., Li, S., Wu, W., Sun, Z., Chen, Y., \& Chen, Z. (2008). Circulating CD4+ CD25+ regulatory T cells correlate with chronic hepatitis B infection. Immunology, 123(1), 57-65.

Ramsdell, F., \& Ziegler, S. F. (2003). Transcription factors in autoimmunity. Current opinion in immunology, 15(6), 718-724.

Ranjbar, M., Solgi, G., Mohammadnia, M., Nikbin, B., Pourmand, G., Ansaripour, B., \& Amirzargar, A. (2012). Regulatory T-cell subset analysis and profile of interleukin (IL)-10, IL-17 and interferon-gamma cytokineproducing cells in kidney allograft recipients with donor cells infusion. Clinical and experimental nephrology, 16(4), 636-646.

Romani, L. (2004). Immunity to fungal infections. Nature Reviews Immunology, 4(1), 11-24.

Rouse, B. T., Sarangi, P. P., \& Suvas, S. (2006). Regulatory T cells in virus infections. Immunological reviews, 212(1), 272-286.

Roushan, M. R. H., Kazemi, S., Rostam, F. F., \& Ebrahimpour, S. (2014). A Study of Brucella Infection in Humans. Crescent Journal of Medical and Biological Sciences, 1(3), 69-75.

Sakaguchi, S. (2005). Naturally arising Foxp3-expressing CD25+ CD4+ regulatory T cells in immunological tolerance to self and non-self. Nature immunology, 6(4), 345-352.

Sakaguchi, S., Wing, K., Onishi, Y., Prieto-Martin, P., \& Yamaguchi, T. (2009). Regulatory T cells: how do they suppress immune responses? International immunology, dxp095.

Salomon, B., Lenschow, D. J., Rhee, L., Ashourian, N., Singh, B., Sharpe, A., \& Bluestone, J. A. (2000). B7/CD28 costimulation is essential for the homeostasis of the CD4+ CD25+ immunoregulatory $\mathrm{T}$ cells that control autoimmune diabetes. Immunity, 12(4), 431-440.

Sathler-Avelar, R., Vitelli-Avelar, D. M., Teixeira-Carvalho, A., \& Martins-Filho, O. A. (2009). Innate immunity and regulatory T-cells in human Chagas disease: what must be understood? Memorias do Instituto Oswaldo Cruz, 104, 246-251.

Scotto, L., Naiyer, A. J., Galluzzo, S., Rossi, P., Manavalan, J. S., Kim-Schulze, S., ... Suciu-Foca, N. (2004). Overlap between molecular markers expressed by naturally occurring CD4+ CD25+ regulatory $\mathrm{T}$ cells and antigen specific CD4+CD25+ and CD8+CD28- T suppressor cells. Human immunology, 65(11), 1297-1306.

Seder, R. A., Marth, T., Sieve, M. C., Strober, W., Letterio, J. J., Roberts, A. B., \& Kelsall, B. (1998). Factors involved in the differentiation of TGF- $\beta$-producing cells from naive CD4+ T cells: IL-4 and IFN- $\gamma$ have opposing effects, while TGF- $\beta$ positively regulates its own production. The Journal of immunology, 160(12), 5719-5728.

Smyth, M. J., Crowe, N. Y., Hayakawa, Y., Takeda, K., Yagita, H., \& Godfrey, D. I. (2002). NKT cellsconductors of tumor immunity? Current opinion in immunology, 14(2), 165-171.

Sojka, D. K., Huang, Y. H., \& Fowell, D. J. (2008). Mechanisms of regulatory T-cell suppression - a diverse arsenal for a moving target. Immunology, 124(1), 13-22. http://dx.doi.org/10.1111/j.1365-2567.2008.02813.x

Soliman, H., Mediavilla-Varela, M., \& Antonia, S. (2010). Indoleamine 2,3-Dioxygenase: Is It an Immune Suppressor? Cancer journal (Sudbury, Mass.), 16(4), 10.1097/PPO.1090b1013e3181eb3343. http://dx.doi.org/10.1097/PPO.0b013e3181eb3343

Sugimoto, K., Ikeda, F., Stadanlick, J., Nunes, F. A., Alter, H. J., \& Chang, K. M. (2003). Suppression of HCVspecific T cells without differential hierarchy demonstrated ex vivo in persistent HCV infection. Hepatology, 38(6), 1437-1448.

Takahashi, M., Nakamura, K., Honda, K., Kitamura, Y., Mizutani, T., Araki, Y., ... Nawata, H. (2006). An inverse correlation of human peripheral blood regulatory $\mathrm{T}$ cell frequency with the disease activity of ulcerative colitis. Digestive diseases and sciences, 51(4), 677-686.

Tarazona, R., DelaRosa, O., Peralbo, E., Casado, J., Pena, J., \& Solana, R. (2003). Human NKT cells in health and disease. Immunologia, 22(4), 359-370. 
Thorborn, G., Pomeroy, L., Isohanni, H., Perry, M., Peters, B., \& Vyakarnam, A. (2010). Increased sensitivity of CD4+ T-effector cells to CD4+CD25+ Treg suppression compensates for reduced Treg number in asymptomatic HIV-1 infection. PLoS One, 5(2), e9254. http://dx.doi.org/10.1371/journal.pone.0009254

Thunberg, S., Gafvelin, G., Nord, M., Grönneberg, R., Grunewald, J., Eklund, A., \& Van Hage, M. (2010). Allergen provocation increases TH2-cytokines and FOXP3 expression in the asthmatic lung. Allergy, 65(3), 311-318.

van der Vliet, H. J., \& Nieuwenhuis, E. E. (2007). IPEX as a result of mutations in FOXP3. Journal of Immunology Research, 2007.

Vlad, G., Cortesini, R., \& Suciu-Foca, N. (2005). License to heal: bidirectional interaction of antigen-specific regulatory T cells and tolerogenic APC. The Journal of immunology, 174(10), 5907-5914.

Vogel, I., Kasran, A., Cremer, J., Kim, Y. J., Boon, L., Van Gool, S. W., \& Ceuppens, J. L. (2015). CD28/CTLA4/B7 costimulatory pathway blockade affects regulatory T-cell function in autoimmunity. European journal of immunology.

Wang, X., Sherman, A., Liao, G., Leong, K. W., Daniell, H., Terhorst, C., \& Herzog, R. W. (2013). Mechanism of oral tolerance induction to therapeutic proteins. Advanced Drug Delivery Reviews, 65(6), 759-773. doi: http://dx.doi.org/10.1016/j.addr.2012.10.013

Wang, Z., Liu, J. Q., Liu, Z., Shen, R., Zhang, G., Xu, J., ... Bai, X. F. Tumor-derived IL-35 promotes tumor growth by enhancing myeloid cell accumulation and angiogenesis: J Immunol. 2013 Mar 1;190(5):2415-23. Epub 2013 Jan 23. http://dx.doi.org/10.4049/jimmunol.1202535.

Weber, M. S., Benkhoucha, M., Lehmann-Horn, K., Hertzenberg, D., Sellner, J., Santiago-Raber, M.-L., ... Lalive, P. H. (2010). Repetitive pertussis toxin promotes development of regulatory $\mathrm{T}$ cells and prevents central nervous system autoimmune disease. PLoS One, 5(12), e16009.

Weiner, H. L. (2001). Oral tolerance: immune mechanisms and the generation of Th3-type TGF-beta-secreting regulatory cells. Microbes and Infection, 3(11), 947-954. http://dx.doi.org/10.1016/S1286-4579(01)01456-3

Weiner, H. L., da Cunha, A. P., Quintana, F., \& Wu, H. (2011). Oral tolerance. Immunological reviews, 241(1), 241-259.

Whibley, N., Maccallum, D. M., Vickers, M. A., Zafreen, S., Waldmann, H., Hori, S., ... Hall, A. M. (2014). Expansion of Foxp3(+) T-cell populations by Candida albicans enhances both Th17-cell responses and fungal dissemination after intravenous challenge. Eur J Immunol, 44(4), 1069-1083. http://dx.doi.org/10.1002/eji. 201343604

Wohlfert, E., \& Belkaid, Y. (2008). Role of Endogenous and Induced Regulatory T Cells During Infections. J Clin Immunol, 28(6), 707-715. doi: 10.1007/s10875-008-9248-6

Wu, K., Bi, Y., Sun, K., \& Wang, C. (2007). IL-10-producing type 1 regulatory T cells and allergy. Cell Mol Immunol, 4(4), 269-275.

Wu, Y. E., Peng, W. G., Cai, Y. M., Zheng, G. Z., Zheng, G. L., Lin, J. H., ... Li, K. (2010). Decrease in CD4+ $\mathrm{CD} 25+$ FoxP3 $+\mathrm{T}$ reg cells after pulmonary resection in the treatment of cavity multidrug-resistant tuberculosis. International Journal of Infectious Diseases, 14(9), e815-e822.

Yazdani, Y., Mohammadnia-Afrouzi, M., Yousefi, M., Anvari, E., Ghalamfarsa, G., Hasannia, H., ... JadidiNiaragh, F. (2015). Myeloid-derived suppressor cells in B cell malignancies. Tumor Biology, 36(10), 73397353.

Zelante, T., De Luca, A., Bonifazi, P., Montagnoli, C., Bozza, S., Moretti, S., ... Mosci, P. (2007). IL-23 and the Th17 pathway promote inflammation and impair antifungal immune resistance. European journal of immunology, 37(10), 2695-2706.

Zorn, E., Nelson, E. A., Mohseni, M., Porcheray, F., Kim, H., Litsa, D., ... Soiffer, R. J. (2006). IL-2 regulates FOXP3 expression in human CD4+ CD25+ regulatory T cells through a STAT-dependent mechanism and induces the expansion of these cells in vivo. Blood, 108(5), 1571-1579.

\section{Copyrights}

Copyright for this article is retained by the author(s), with first publication rights granted to the journal.

This is an open-access article distributed under the terms and conditions of the Creative Commons Attribution license (http://creativecommons.org/licenses/by/4.0/). 